\title{
Maternal Distraction During Breast- and Bottle Feeding Among WIC and non-WIC Mothers
}

\author{
Alison K. Ventura, PhD; Simone Teitelbaum, BS
}

\begin{abstract}
Objective: To explore the prevalence and correlates of maternal distraction during infant feeding within a sample of mothers enrolled or not in the Special Supplemental Nutrition Program for Woman, Infants, and Children (WIC).

Design: Mothers kept diaries of their infants' feeding patterns.

Participants: Mothers $(\mathrm{n}=75)$ with infants aged $\leq 6$ months.

Main Outcome Measures: Within the diaries, mothers recorded what else, if anything, they did during the feeding. Mothers also completed questionnaires on demographics, feeding styles, and infant temperament and eating behaviors.

Analysis: Mothers' responses were coded into thematic categories. Feedings were classified as distracted when the mothers reported doing something other than feeding and/or interacting with the infant. Logistic regression was used to explore whether mothers exhibited different levels of distraction when breastfeeding (BF) vs bottle feeding. The researchers used multiple stepwise regression to explore associations between distracted feeding and characteristics of mothers and infants.

Results: Distractions were reported during 43\% of feedings; $26 \%$ involved technological distractors. Mothers who were multiparous and perceived that their infants had greater appetites reported greater levels of any distraction during feeding. Mothers who were of racial/ethnic minorities, adhered to laisse $z$ faire feeding style, had younger infants, and perceived their infants to have lower food responsiveness and greater appetite reported greater levels of technological distraction. Being enrolled in WIC was not associated with mothers levels of distracted feeding.

Conclusions and Implications: Mothers reported a wide variety of distractions during both BF and bottle feeding; higher levels of distraction were associated with characteristics of both mothers and infants. Further research is needed to understand whether and how maternal distraction affects feeding outcomes. Awareness of such distractions and their potential impact would be useful to practitioners working with pregnant and postpartum women.
\end{abstract}

Key Words: responsive feeding, distracted feeding, bottle feeding, breastfeeding, child development (J Nutr Educ Behav. 2017;49:S169-S176.)

Accepted April 14, 2017.

\section{INTRODUCTION}

A growing body of research highlighted the importance of caregiver sensitivity and responsiveness during feeding for promoting infants' abilities to self-regulate intake ${ }^{1}$ and healthy infant weight gain trajectories. ${ }^{2}$ In addition, caregivers' sensitivity and responsiveness in both feeding and non-feeding contexts help infants develop effective emotional, cognitive, and behavioral self-regulatory abilities, ${ }^{3}$ which are predictive of significantly better stress reactivity, ${ }^{4}$ lower risk for internalizing and externalizing problems, ${ }^{5}$ and lower risk of obesity and related comorbidities ${ }^{6,7}$ during later life. Thus, it is well established that an important foundation for promoting healthy development during

Department of Kinesiology, California Polytechnic State University, San Luis Obispo, CA Conflict of Interest Disclosure: The authors' conflict of interest disclosures can be found online with this article on www.jneb.org.

Address for correspondence: Alison K. Ventura, PhD, Department of Kinesiology, California Polytechnic State University, One Grand Ave, 43A-371, San Luis Obispo, CA 93407; Phone: (805) 756-5693; Fax: (805) 756-7273; E-mail: akventur@calpoly.edu

(C)2017 Society for Nutrition Education and Behavior. Published by Elsevier, Inc. All rights reserved.

http://dx.doi.org/10.1016/j.jneb.2017.04.004

Journal of Nutrition Education and Behavior • Volume 49, Number 7S2, 2017

early childhood is the promotion of caregivers' sensitivity and responsiveness during caregiver-infant interactions. However, the Institute of Medicine ${ }^{8}$ and others ${ }^{9}$ highlighted the surprising paucity of research aimed at understanding how to promote caregivers' sensitivity and responsiveness within feeding contexts and the need for more research in this field. This is especially true for low-income and racial/ethnic minority caregivers, who are more likely to use non-responsive feeding practices ${ }^{10-12}$ and whose infants are at higher risk for rapid weight gain and obesity. ${ }^{13-15}$

Although there are many reasons why caregivers may exhibit low responsiveness to infant cues during feeding interactions, few studies examined how maternal distraction (eg, watching 
television [TV], using a mobile device) may affect infant feeding interactions and outcomes. ${ }^{16-19}$ Research in older children and adults illustrated that distracted eating is a common occurrence ${ }^{20}$ and that eating while engaging with technological distractions has an impact on meal outcomes, leading to lower awareness of satiety cues and overeating compared with meals when no distractions are present. ${ }^{21,22}$ Few studies examined whether distracted feeding has similar and/or unique impacts on caregiver-child feeding interactions.

Given the ever-increasing accessibility of handheld technologies and ondemand entertainment, ${ }^{23}$ even among lower-income, minority populations, ${ }^{24,25}$ combined with the large number of feedings required by young infants on a daily basis, ${ }^{26}$ it is possible that many caregivers regularly attend to distractors while feeding their infants as a means to cope with the large volume of time they must dedicate to feeding. Indeed, in a recent study of bottlefeeding dyads, mothers reported distractions during $52 \%$ of bottle feedings; almost one third of these feedings involved technological distractors. ${ }^{19}$ In addition, in a laboratory-based study, mothers who were distracted while bottle feeding their infants were significantly less sensitive to their infants' cues than were mothers who were not distracted. ${ }^{18}$ These previous studies also illustrated that tendencies toward distracted feeding were associated with certain maternal characteristics such as age and parity, ${ }^{19}$ and that associations between distraction and feeding outcomes may be moderated by dimensions of infant temperament ${ }^{18}$ such as infants' abilities to self-regulate (ie, orienting/regulation capacities) and levels of impulsivity (ie, surgency/extraversion).

Because these previous findings focused solely on bottle-feeding mothers, further research is needed to understand whether similar levels of distraction are present in breastfeeding (BF) dyads and whether certain mother-infant dyads are more likely than others to engage in distracted feeding. To this end, the objective of the current study was to explore further the prevalence of maternal distraction within a sample of both BF and bottle-feeding participants enrolled or not in the Special Supplemental Nutrition Program for Woman, Infants, and Children (WIC).
A secondary aim of this study was to examine whether maternal (ie, feeding mode, WIC status, education, race/ ethnicity, parity, body mass index [BMI], feeding styles) and infant (ie, sex, age, weight status, temperament, eating behaviors) characteristics were associated with mothers' tendencies toward distracted feeding. Based on findings of previous research focused on distracted feeding, ${ }^{18,19}$ it was hypothesized that higher levels of distraction would be associated with greater maternal age and parity and lower levels of responsive feeding style. In addition, previous research illustrated that BF mothers exhibited greater tendencies toward responsive feeding ${ }^{27,28}$; accordingly, it was hypothesized that bottle-feedingmothers would show greater tendencies toward distracted feeding than would BF mothers. Finally, given previous research illustrating the importance of maternal responsiveness for infants' developing abilities to self-regulate, it was hypothesized that greater levels of maternal distraction would be associated with lower general (ie, orienting/regulation capacity dimension of temperament) and feeding-specific (ie, food responsiveness and satiety responsiveness dimensions of infant eating behaviors) self-regulatory capacities for infants.

\section{METHODS}

\section{Participants and Recruitment}

Mothers $(\mathrm{n}=75)$ who participated in infant feeding studies $^{18,19,29}$ were asked to keep a diary of their infants' feeding patterns for 1-6 days (total number of records $=476$; total number of recorded feedings $=2,982$ ). Feeding record data for a subset of 41 formulafeeding infants were published previously. ${ }^{9}$ Inclusion criteria for infants were that they were: (1) healthy, (2) born full-term, (3) aged between birth and 6 months; and (4) not yet introduced to solid foods. Inclusion criteria for mothers were that they: (1) were aged 18-40 years and (2) did not have gestational diabetes or any complications during pregnancy or birth that led to infant feeding problems. Both BF and formula-feeding dyads were included in the current study. Participants were recruited through fliers posted in offices of the WIC BF support groups, libraries, coffee shops, and local pediatric offices, as well as through targeted Facebook advertisements. Mothers were provided $\$ 25$ cash compensation for participation. All study procedures were reviewed under expedited review and approved by the institutional review board at California Polytechnic State University. Both oral and written informed consent was obtained from each mother.

\section{Procedures and Measures}

Mothers received feeding records via postal mail or e-mail. Through both verbal instruction by a research assistant and written instructions on the form, mothers were asked to record, for each feeding: (1) start and end time; (2) what was fed (eg, formula, breast milk from the breast, breast milk from a bottle); (3) amount fed (if possible); and (4) what else, if anything, they were doing while feeding their infants.

Printed records were collected from all mothers during a laboratory visit several days later, when mothers also completed a demographic questionnaire. Mothers also completed the Infant Behavior Questionnaire-Revised Very Short Form, which assessed infants' levels of surgency/extraversion, orienting/regulation capacity, and negative affect (subscale scores ranged from 1 to 7$)^{30}$; the Infant Feeding Style Questionnaire, ${ }^{31}$ which assessed mothers' self-reported laissez-faire (example item: I think it is okay to prop an infant's bottle), restrictive (example item: It's important for the parent to decide how much an infant should eat), pressuring (example item: I try to get my child to eat even if she or he seems not hungry), and responsive (example item: $M y$ child knows when she or he is hungry and needs to eat) feeding styles (all subscale scores ranged from 1 to 5); and the Baby Eating Behavior Questionnaire, ${ }^{32}$ which assessed mothers' perceptions of infants' levels of enjoyment of food, food responsiveness, satiety responsiveness, slowness in eating, and general appetite (subscale scores ranged from 1 to 5). All questionnaire subscales showed good internal consistency in this sample, with Cronbach $\alpha$ scores ranging from acceptable $(\alpha=.70-.79)$ to $\operatorname{good}(\alpha=.80-.89)$ : the Infant Behavior QuestionnaireRevised Very Short Form subscales 
ranged from $\alpha=.78$ to .83 , the Infant Feeding Style Questionnaire subscales ranged from $\alpha=.70$ to .85 , and the Baby Eating Behavior Questionnaire subscales ranged from $\alpha=.71$ to .87 .

A trained research assistant collected weight and length or height measurements in triplicate for infants and mothers using an infant scale and infantometer (Models 374 and 233; Seca, Hamburg, Germany) and an adult scale and stadiometer (Model 763; Seca), respectively. Infant anthropometric data were later normalized to z-scores using the World Health Organization Anthro software (version 3.0.1). Mothers' weight and height were used to calculate BMI (in $\mathrm{kg} / \mathrm{m}^{2}$ ).

\section{Data Analysis}

Mothers' responses to the question What else, if anything, were you doing while feeding your infants? were sorted into thematic categories using constant comparison within the framework of grounded theory. ${ }^{33}$ Before coding, the first author developed a coding manual with an initial list of themes found in previous research examining the prevalence of distraction among bottle-feeding dyads. ${ }^{19}$ Three trained coders independently coded all records based on the coding manual, but also identified additional themes not present in the previous research. Results were then reviewed and compared for validity, and any discrepancies in theme identification or coding were discussed. Intercoder reliability was established by comparing the common coding of a total of 10 records by all coders. Cohen's kappa for correspondence among coders was $>0.80$, indicating good reliability among coders. ${ }^{34}$

After coding was complete, themes were used to classify feedings into 2 categories: (1) mother was distracted (eg, watching TV, using a computer) vs (2) mother was not distracted (eg, nothing was specified, interacting with the infant). Distractions were also further classified into technological (eg, watching TV, using a computer, smartphone, or tablet) vs not (eg, reading, doing housework). To obtain a measure of each mothers' intensity of distracted feeding, the percentage of feedings during which the mother reported any distraction was calculated for each mother $(=$ [number of feedings in which a distraction was reported/total number of feedings reported] $\times 100$ ). Similarly, the percentage of feedings during which the mother reported technological distractions was calculated for each mother (= [number of feedings in which a technological distraction was reported/total number of feedings reported] $\times 100$ ).

All quantitative analyses were conducted using SAS (version 9.4; SAS Institute, Inc, Cary NC; 2013). Descriptive statistics were calculated to summarize sample demographics, mothers' frequency of different activities during reported feedings, and distracted vs not distracted feeding. Characteristics of participants who were or were not enrolled in WIC were compared using ANOVA and chi-square tests of independence. Mixed-effects models were used to examine associations between mothers' reported feeding durations and reports of any type of distraction or technological distraction during feeding, while also controlling for within-person correlation among repeated measurements of feeding durations and distractions.

To explore whether mothers exhibited different levels of distraction when they were BF vs bottle feeding, the researchers used logistic regression with estimation via generalized estimating equations to determine whether feeding mode during each recorded feeding predicted the probability of mothers' reports of distracted vs not distracted feeding. Logistic regression models accounted for the within-person correlation among repeated measurements for valid estimation of associations between feeding mode and types of distraction, and associated SEs.

To explore associations between distracted feeding and characteristics of mothers (ie, feeding mode, WIC status, education, race/ethnicity, parity, BMI, feeding styles) and infants (ie, sex, age, weight status, temperament, eating behaviors), multiple stepwise regression was used to determine the combination of infant and maternal characteristics that best predicted mothers' intensities of any distractions and technological distractions during feeding. Categorical variables were dummy coded before inclusion in regression models (ie, feeding mode, mothers' education level [high school degree or less vs some college or college degree], mothers' race/ethnicity [white vs black, Hispanic, or other]). In addition, all assumptions for multicollinearity of predictors, homoscedasticity, normality of residuals, and linearity were assessed before all linear regression analyses. When applicable, results are presented as percentages (n) or mean \pm SD. $P<.05$ was used to indicate significant differences.

\section{RESULTS}

\section{Sample Characteristics}

Table 1 summarizes sample characteristics for mothers enrolled or not in WIC. As illustrated in Table 1, infants enrolled in WIC were significantly younger and had significantly higher weight-for-length z-scores than did infants not enrolled in WIC. Mothers participating in WIC were significantly younger, had significantly higher BMI, and had more children than did nonparticipating mothers. Similar to national data on characteristics of WIC participants, ${ }^{35}$ mothers enrolled in WIC reported significantly lower family incomes and education levels than did mothers not enrolled in WIC and greater proportions of mothers who were enrolled were racial/ethnic minorities and were formula/bottle feeding compared with those who were not enrolled in the program. Perceptions of their infants and their feeding styles of mothers enrolled or not in WIC also differed: mothers who were enrolled in the program reported that their infants had significantly lower levels of negative affect, satiety responsiveness, and slowness in eating, and greater enjoyment of food compared with mothers who were not participating in WIC, and also reported more restrictive and less responsive feeding styles.

\section{Prevalence of Maternal Distraction During Feeding}

Table 2 presents results of the thematic analysis of mothers' feeding records. Mothers reported a variety of additional activities while feeding their infants, which were further categorized into technological vs non-technological distractions. Distractions were reported during $43 \%$ of feedings, with mothers reporting technological distractions during $26 \%$ of feedings and nontechnological distractions during $17 \%$ 
Table 1. Sample Characteristics by Enrollment in $\mathrm{WIC}^{\mathrm{a}}$

\begin{tabular}{|c|c|c|c|}
\hline Characteristic & $\begin{array}{c}\text { Mothers } \\
\text { Enrolled in } \\
\text { WIC }(n=46)\end{array}$ & $\begin{array}{l}\text { Mothers Not } \\
\text { Enrolled in } \\
\text { WIC }(n=29)\end{array}$ & $\chi^{2}$ or $\mathbf{F}$ \\
\hline \multicolumn{4}{|l|}{ Infant characteristics } \\
\hline Sex, female (\%) & $54(25)$ & $48(14)$ & 0.26 \\
\hline Age, wk & $14 \pm 7$ & $18 \pm 7$ & $5.72^{*}$ \\
\hline Weight-for-length z-score & $1 \pm 1$ & $0 \pm 1$ & $10.47^{\star \star}$ \\
\hline $\begin{array}{l}\text { Temperament subscales }^{\mathrm{b}} \\
\text { Surgency/extraversion } \\
\text { Orienting/regulation capacity } \\
\text { Negative affect }\end{array}$ & $\begin{array}{l}4 \pm 1 \\
6 \pm 1 \\
3 \pm 1\end{array}$ & $\begin{array}{l}5 \pm 1 \\
6 \pm 1 \\
4 \pm 1\end{array}$ & $\begin{array}{c}1.41 \\
1.06 \\
10.96 \text { ** }\end{array}$ \\
\hline $\begin{array}{l}\text { Eating behavior subscales }{ }^{c} \\
\text { Enjoyment of food } \\
\text { Food responsiveness } \\
\text { Satiety responsiveness } \\
\text { Slowness in eating } \\
\text { General appetite }\end{array}$ & $\begin{array}{l}5 \pm 1 \\
3 \pm 1 \\
2 \pm 1 \\
2 \pm 1 \\
3 \pm 1\end{array}$ & $\begin{array}{l}4 \pm 1 \\
3 \pm 1 \\
3 \pm 1 \\
3 \pm 1 \\
4 \pm 1\end{array}$ & $\begin{array}{l}14.88^{\star \star} \\
1.60 \\
17.16^{\star \star} \\
16.19^{\star \star} \\
3.01\end{array}$ \\
\hline \multicolumn{4}{|l|}{ Maternal/familial characteristics } \\
\hline Age, y & $27 \pm 6$ & $32 \pm 4$ & $13.05^{\star \star}$ \\
\hline Body mass index, $\mathrm{kg} / \mathrm{m}^{2}$ & $31 \pm 6$ & $27 \pm 7$ & $6.53^{\star}$ \\
\hline Parity, primiparous (\%) & $37(17)$ & $72(21)$ & $8.95^{\star *}$ \\
\hline $\begin{array}{l}\text { Annual family income level } \\
\quad<\$ 15,000 \\
\$ 15,000 \text { to } \$ 34,999 \\
\$ 35,000 \text { to } \$ 74,999 \\
\geq \$ 75,000 \\
\text { Not reported }\end{array}$ & $\begin{array}{l}41(19) \\
35(16) \\
17(8) \\
0(0) \\
7(3)\end{array}$ & $\begin{array}{c}0(0) \\
3(1) \\
10(3) \\
72(21) \\
14(4)\end{array}$ & $54.57^{\star \star}$ \\
\hline $\begin{array}{l}\text { Level of education } \\
\text { Did not complete high school } \\
\text { High school degree } \\
\text { Some college } \\
\text { Bachelors or graduate degree } \\
\text { Not reported }\end{array}$ & $\begin{array}{c}12(5) \\
39(18) \\
35(16) \\
11(5) \\
4(2)\end{array}$ & $\begin{array}{c}0(0) \\
0(0) \\
14(4) \\
86(25) \\
0(0)\end{array}$ & $42.23^{\star \star}$ \\
\hline $\begin{array}{l}\text { Racial/ethnic category } \\
\text { Non-Hispanic white } \\
\text { Non-Hispanic black } \\
\text { Hispanic white } \\
\text { Hispanic black } \\
\text { Asian/Pacific Islander } \\
\text { Native American }\end{array}$ & $\begin{aligned} 26 & (12) \\
61 & (28) \\
2 & (1) \\
7 & (3) \\
2 & (1) \\
2 & (1)\end{aligned}$ & $\begin{array}{l}76(22) \\
3(1) \\
14(4) \\
0(0) \\
7(2) \\
0(0)\end{array}$ & $32.00^{* *}$ \\
\hline $\begin{array}{l}\text { Feeding styles subscales } \\
\text { Laissez-faire }^{d} \\
\text { Pressuring } \\
\text { Restrictive } \\
\text { Responsive }\end{array}$ & $\begin{array}{l}2 \pm 1 \\
2 \pm 1 \\
4 \pm 1 \\
4 \pm 1\end{array}$ & $\begin{array}{l}3 \pm 1 \\
2 \pm 1 \\
3 \pm 1 \\
5 \pm 0\end{array}$ & $\begin{array}{c}2.40 \\
0.39 \\
19.92^{\star \star} \\
10.79^{\star \star}\end{array}$ \\
\hline $\begin{array}{l}\text { Feeding characteristics } \\
\text { Milk type } \\
\text { Exclusively breast milk } \\
\text { Exclusively formula } \\
\text { Mix of breast milk } \\
\text { and formula }\end{array}$ & $\begin{array}{c}9(4) \\
76(35) \\
15(7)\end{array}$ & $\begin{array}{c}72(21) \\
10(3) \\
17(5)\end{array}$ & $36.88^{\star *}$ \\
\hline
\end{tabular}

(continued) of feedings. For the remaining $57 \%$ of feedings, mothers reported interacting with their infants or that they did not do anything else during the feeding, or they left the question blank. Reported feeding durations were not associated with reports of any type of distraction $\left(\mathrm{F}_{1,2784}=0.19 ; P=.66\right)$ or technological distraction $\left(\mathrm{F}_{1,2784}=\right.$ $0.05 ; P=.82$ ) during feeding.

Of the 2,982 reported feedings, 36\% ( $\mathrm{n}=1,075$ ) were BFs (ie, from the breast) and $64 \%$ were bottle feedings ( $\mathrm{n}=1,906$; note that feeding mode was not reported for 1 feeding). Of bottle feedings, $72 \%(\mathrm{n}=1,367)$ were formula, 26\% ( $\mathrm{n}=500)$ were expressed breast milk, and $2 \%(n=39)$ were a combination of breast milk and formula. Table 3 presents the percentages and odds of mothers' reports of any, technological, or no distractions as a function of feeding mode (BF vs bottle feeding) during the recorded feeding. Overall, mothers had similar odds of reporting any distraction $(P=.68)$, technological distractions $(P=.37)$, non-technological distractions $(P=.67)$, or no distractions $(P=.68)$ during BFs vs bottle feedings.

\section{Mothers' Intensities of Distracted Feeding}

When analyzed at the level of the individual, $92 \%$ of mothers reported a distraction during at least 1 feeding. A total of $83 \%$ of mothers reported a technological distraction during $\geq 1$ feedings. Mothers' reports of distractions ranged from $0 \%$ to $100 \%$ of recorded feedings (mean $=43.9 \%$; $\mathrm{SD}=29.5 \%$ ); similarly, reports of technological distractions ranged from $0 \%$ to $97 \%$ of recorded feedings (mean = $27.7 \%$; $\mathrm{SD}=24.0 \%$ ).

\section{Associations Between Mothers' Intensities of Distracted Feeding and Infant and Mother Characteristics}

Table 4 illustrates the best-fit models for predicting mothers' intensities of any distraction and technological distractions. Significant predictors of mothers' intensities of any distraction during feeding were multiparity and 
Table 1. Continued

\begin{tabular}{cccc} 
Characteristic & $\begin{array}{c}\text { Mothers } \\
\text { Enrolled in } \\
\text { WIC (n=46) }\end{array}$ & $\begin{array}{c}\text { Mothers Not } \\
\text { Enrolled in } \\
\text { WIC (n=29) }\end{array}$ & $\boldsymbol{\chi}^{\mathbf{2}}$ or F \\
Feed mode & & & $35.62^{\star *}$ \\
Exclusively breastfed & $2(1)$ & $14(4)$ & \\
Exclusively bottle fed & $89(41)$ & $21(6)$ & \\
Mix of breast and bottle & $9(4)$ & $66(19)$ & \\
\hline
\end{tabular}

WIC indicates the Special Supplemental Nutrition Program for Woman, Infants, and Children.

${ }^{a}$ Data are from mothers enrolled or not in WIC $(n=75)$ with infants aged $\leq 6$ mo who participated in infant feeding studies; ${ }^{\mathrm{b}}$ From the Infant Behavior Questionnaire-Revised Very Short Form ${ }^{30}$ (possible score range: 1-7); ${ }^{\mathrm{C}}$ From the Baby Eating Behavior Questionnaire ${ }^{32}$ (possible score range: 1-5); ${ }^{\mathrm{d}}$ From the Infant Feeding Style Questionnaire ${ }^{31}$ (possible score range: $1-5$ ); ${ }^{\star} P<.05$; ${ }^{\star \star} P<.01$ for difference between mothers enrolled or not in WIC.

Note: Values are presented as \% ( $\mathrm{n}$ ) or mean $\pm \mathrm{SD}$ and compared using chi-square tests of independence.

mothers' perception of greater infant appetite. Significant predictors of mothers' intensities of technological distraction during feeding were mothers' racial/ ethnic minority (eg, black, Hispanic, or Asian) status, adherence to a more laissez-faire feeding style, younger infant age, and perception of lower infant food responsiveness and greater infant appetite. Feeding mode; whether the mother was enrolled in WIC, education, and BMI; and infant sex, weight status, and temperament were not sig- nificant predictors of distraction in either model.

\section{DISCUSSION}

The current study aimed to describe 1 potential barrier to responsive feeding that is particularly relevant in today's technology-focused society: the presence of and engagement with distractions during infant feeding. Findings from the study illustrated that distracted
Table 2. Proportions of Feedings in Which Mothers Reported Distractions Vs No Distractions $^{\mathrm{a}}$

\begin{tabular}{lrr} 
Themes & \% & n \\
Technological distraction reported & 26 & 775 \\
Watching television & 20 & 580 \\
Using a smartphone or tablet & 5 & 161 \\
Using a computer & 1 & 26 \\
Multiple technologies & 0 & 8 \\
Non-technological distraction reported & 17 & 504 \\
Talking on phone or to another adult & 4 & 122 \\
Sleeping & 4 & 120 \\
Reading newspaper, book, or magazine & 3 & 91 \\
Listening to music & 2 & 60 \\
Doing housework/caring for other children & 2 & 52 \\
Eating & 1 & 36 \\
Traveling & 1 & 23 \\
No distractions reported & 57 & 1,703 \\
Nothing specified & 52 & 1,544 \\
Interacting with baby & 5 & 159 \\
\hline
\end{tabular}

${ }^{a}$ Data are from mothers enrolled or not in the Special Supplemental Nutrition Program for Woman, Infants, and Children $(n=75)$ with infants aged $\leq 6$ mo who participated in infant feeding studies; these analyses were based on 2,982 recorded feedings. feeding is a common practice for both mothers who were and were not enrolled in WIC, regardless of mode of feeding. Although few studies described the extent to which caregivers engaged in distractions during feeding and other caregiver-child interactions, the findings of the current study were consistent with previous studies focused on bottle-feeding dyads ${ }^{19}$ and families with older children, ${ }^{16,17}$ illustrating that significant proportions of caregivers frequently engaged with technological and other environmental stimuli during child feeding and mealtime interactions.

The significance of caregiver responsiveness during feeding interactions is underlined by the belief that infants have an innate capacity to self-regulate $^{36,37}$ that develops during the first few months postpartum and that this development is shaped by interactional learning that occurs when the caregiver responds contingently and appropriately to infant cues. ${ }^{1}$ During early infancy, feeding interactions comprise a significant proportion of caregiver-infant interactions; thus, high-quality, synchronous feeding interactions provide the infant with both nutritive and socioemotional benefits. ${ }^{38-43}$ In light of this understanding, an important question is whether the presence of certain distractions during feeding interactions affect the responsiveness of caregivers to children's cues and needs.

The current study tested several hypotheses aimed at understanding whether certain dyads may be more prone to distracted feeding than others. Inconsistent with previous research, 19,27,28 hypothesized associations were not found between distracted feeding and $\mathrm{BF}$, mothers' age and self-reported tendencies toward responsive feeding, and infants' temperamental characteristics. However, the current study supported hypothesized associations between distracted feeding and parity and infant eating behaviors. Interpretation of these findings within the broader context of previous research on caregiver feeding practices and styles reveals a number of consistencies. Previous research similarly found that multiparous mothers reported greater levels of distraction during infant feeding, ${ }^{19}$ which makes intuitive sense given the increased number of children for whom these mothers cared. Although further research is needed to verify whether distracted feeding is a facet 
Table 3. Odds of Reporting Technological Distractions, Non-technological Distractions, or No Distractions During BFs Vs Bottle Feedings $^{a}$

BFs

\begin{tabular}{|c|c|c|c|c|c|c|}
\hline Themes & $\%$ & $\mathbf{n}$ & $\%$ & $\mathbf{n}$ & $\begin{array}{c}\text { Odds Ratio (95\% } \\
\text { Confidence Interval) }^{\mathrm{b}, \mathrm{c}}\end{array}$ & $\boldsymbol{P}$ \\
\hline Technological distraction reported & 23 & 249 & 28 & 526 & $0.79(0.48-1.32)$ & .37 \\
\hline Watching television & 11 & 115 & 25 & 465 & & \\
\hline Using smartphone or tablet & 10 & 111 & 3 & 50 & & \\
\hline Using computer & 2 & 16 & 1 & 10 & & \\
\hline Multiple technologies & 1 & 7 & 0 & 1 & & \\
\hline Non-technological distraction reported & 18 & 193 & 16 & 311 & $1.12(0.66-1.92)$ & 67 \\
\hline Sleeping & 4 & 44 & 4 & 76 & & \\
\hline Talking on phone or to another adult & 3 & 35 & 5 & 87 & & \\
\hline Reading newspaper, book, or magazine & 6 & 59 & 2 & 32 & & \\
\hline Listening to music & 3 & 31 & 2 & 29 & & \\
\hline Doing housework/caring for other children & 0 & 3 & 3 & 49 & & \\
\hline Eating & 2 & 17 & 1 & 19 & & \\
\hline Traveling & 0 & 4 & 1 & 19 & & \\
\hline No distractions reported & 59 & 633 & 56 & 1,070 & $1.12(0.65-1.93)$ & .68 \\
\hline Nothing specified & 53 & 564 & 51 & 980 & & \\
\hline Interacting with baby & 6 & 69 & 5 & 90 & & \\
\hline
\end{tabular}

BF indicates breastfeeding; WIC, Special Supplemental Nutrition Program for Woman, Infants, and Children.

${ }^{a}$ Data are from mothers enrolled or not in WIC $(n=75)$ with infants aged $\leq 6$ mo who participated in infant feeding studies; these analyses were based on 2,982 recorded feedings; ${ }^{b}$ For the logistic regression with estimation via generalized estimating equations model exploring whether feeding mode predicted the probability of mothers' reports of each activity, BF was specified as the referent group; 'WIC participation did not moderate effects of feeding mode on the probability of mothers' reports of each activity.

of non-responsive feeding, the finding that minority race/ethnicity was a significant predictor of technological distraction is consistent with previous research illustrating that racial/ethnic minorities were more likely to report using practices characterized by low responsiveness to child cues. ${ }^{12,44}$ In addition, the association between higher levels of technological distraction and adherence to a laissez-faire feeding style makes intuitive sense because a laissez-faire feeding style is characterized by feeding practices low in involvement and structure (eg, propping the bottle, watching TV during feeding). ${ }^{31}$ Taken together, these findings suggest that a number of factors, such as family structure, cultural beliefs, and broader feeding practices and styles, influence mothers' tendencies toward distracted feeding and abilities to engage in responsive feeding.

However, the limitations of the current study underline possible caveats to this interpretation. First, the correlational and self-report nature of this study precludes abilities to determine cause and effect relationships. For example, because infant eating behaviors

Table 4. Associations Between Characteristics of Mothers and Infants and Mothers' Intensities of Any Distraction and Technological Distraction During Feeding ${ }^{a}$

\begin{tabular}{|c|c|c|c|c|c|}
\hline Model & Dependent Variable & Independent Variables & Coefficient $^{\mathrm{b}}$ & SE & $\boldsymbol{P}$ \\
\hline \multirow[t]{2}{*}{1} & Intensity of any distraction ${ }^{c}$ & Multiparous (vs primiparous) & 18.27 & 7.43 & .02 \\
\hline & $\left(\mathrm{F}_{6.38} ; P=.003 ; \mathrm{R}^{2}=0.20\right)$ & Infant appetite & 10.91 & 3.47 & .003 \\
\hline \multirow[t]{5}{*}{2} & Intensity of technological distraction ${ }^{d}$ & White (vs black, Hispanic, or other) & -13.56 & 4.93 & .008 \\
\hline & $\left(\mathrm{F}_{9.10} ; P<.001 ; \mathrm{R}^{2}=0.48\right)$ & Mother laissez-faire feeding style & 6.83 & 2.75 & .02 \\
\hline & & Infant age & -0.83 & 0.35 & .02 \\
\hline & & Infant food responsiveness & -13.66 & 3.62 & $<.001$ \\
\hline & & Infant appetite & 11.37 & 2.64 & $<.001$ \\
\hline
\end{tabular}

$\mathrm{R}^{2}$ indicates multivariate coefficient; WIC, the Special Supplemental Nutrition Program for Woman, Infants, and Children.

aData are from mothers enrolled or not in WIC $(n=75)$ with infants aged $\leq 6$ mo who participated in infant feeding studies; ${ }^{b}$ For multiple stepwise regression models exploring the combination of maternal (ie, feeding mode, education, race/ethnicity, parity, WIC status, body mass index, feeding styles) and infant (ie, sex, age, weight status, temperament, eating behaviors) characteristics that predicted maternal intensity of any or technological distraction; ${ }^{\circ}$ Calculated for each mother as: (number of feedings in which any distraction was reported)/(total number of feedings reported) $\times 100$; ${ }^{\mathrm{d}}$ Calculated for each mother as: (number of feedings in which a technological distraction was reported)/(total number of feedings reported) $\times 100$. 
(eg, appetite, food responsiveness) were reported by mothers, it is unclear whether maternal distraction influences the development of infants' appetite and food responsiveness or whether mothers who perceive their infants to have larger appetites and lower food responsiveness attend to distractions during the feeding for other reasons (eg, they feel the feeding takes too long). Second, the main variable of interest was assessed through an open-ended question on an infant feeding diary. A strength of this approach is that it provided rich qualitative data on the wide array of things mothers do while feeding their infants. However, it is also possible that mothers underreported their levels of distraction because selfreported engagement in some distractors tends to be biased, such as mobile devices, which are used in short bouts, interspersed through the day. ${ }^{45}$ In a related manner, interpretation of this thematic analysis of maternal reports is also limited by the fact that when a mother left a section blank, it was not known whether this was because no distractions were present or whether the mother failed to report. Mothers were not provided instruction regarding when to complete the records (eg, in real time vs at the end of the day); for those who completed records during the feeding, the records may actually have introduced an additional source of distraction. Finally, although associations between feeding mode and distraction were explored, only 5 participants were exclusively BF and 23 were BF and bottle feeding; thus, although a substantial number of BFs were recorded, these feedings came from a limited number of participants, which limits the generalizability of the findings.

\section{IMPLICATIONS FOR RESEARCH AND PRACTICE}

An important focus for future research is to determine what impact, if any, distracted feeding has on the quality and outcome of the feeding interaction in the short term and on infants' developing eating behaviors and self-regulatory abilities in the long term. In addition, given evidence for interindividual variability in mothers' level of respon- siveness during feeding interactions, ${ }^{38,43,46-49}$ future research should explore whether certain psychosocial factors, such as responsive feeding skills, postpartum depression, participation in WIC or other federal assistance programs, or cultural beliefs, moderate the potential impact of distractors on feeding outcomes. This research would elucidate whether distracted feeding is a form of non-responsive feeding or whether some mothers are still able to feed responsively even in the presence of technological or other distractions.

Further research using experimental designs and/or observational measures of maternal and infant behavior in the presence of environmental distractors is needed to understand better the extent to which mothers attended to distractors vs their infant during feeding and the extent to which the presence of distractors affects feeding interactions. If future research suggests that maternal distraction decreases the quality of the feeding interaction, targeted efforts within both research and practice should focus on educating mothers and other caregivers about the potential effects of caregiver distraction on infant feeding and developmental outcomes. Efforts to develop and evaluate approaches to help caregivers better understand and attend to their infants' cues, especially in the presence of technological and other distractors, may also be warranted.

\section{ACKNOWLEDGMENTS}

This project described was supported by a Simms/Mann Institute Faculty Fellowship, the Eunice Kennedy Shriver National Institute of Child Health and Human Development of the National Institutes of Health under Award No. R03HD080730, and a Drexel College of Nursing and Health Professions research grant. The content is solely the responsibility of the authors and does not necessarily represent the official views of the National Institutes of Health. The authors thank the mothers and infants who participated in this study.

\section{REFERENCES}

1. DiSantis KI, Hodges EA, Johnson SL, Fisher JO. The role of responsive feeding in overweight during infancy and toddlerhood: a systematic review. Int J Obes (Lond). 2011;35:480-492.

2. Farrow C, Blissett J. Does maternal control during feeding moderate early infant weight gain? Pediatrics. 2006;118:e293-e298.

3. Leerkes EM, Wong MS. Infant distress and regulatory behaviors vary as a function of attachment security regardless of emotion context and maternal involvement. Infancy. 2012;17:455-478.

4. van Bakel HJ, Riksen-Walraven JM. Stress reactivity in 15-month-old infants: links with infant temperament, cognitive competence, and attachment security. Dev Psychobiol. 2004;44:157-167.

5. Lyons-Ruth K, Block D. The disturbed caregiving system: relations among childhood trauma, maternal caregiving, and infant affect and attachment. Infant Mental Health J. 1996;17:257-275.

6. Miller AL, Rosenblum KL, Retzloff LB, Lumeng JC. Observed self-regulation is associated with weight in low-income toddlers. Appetite. 2016;105:705-712.

7. Power TG, Olivera YA, Hill RA, et al. Emotion regulation strategies and childhood obesity in high risk preschoolers. Appetite. 2016;107:623-627.

8. Institute of Medicine. Early Childhood Obesity Prevention Policies. Washington, DC: National Academies Press; 2011.

9. Lumeng JC, Taveras EM, Birch L, Yanovski SZ. Prevention of obesity in infancy and early childhood: a National Institutes of Health workshop. JAMA Pediatr. 2015;169:484-490.

10. Gross RS, Fierman AH, Mendelsohn AL, et al. Maternal perceptions of infant hunger, satiety, and pressuring feeding styles in an urban Latina WIC population. Academic Pediatr. 2010;10:29-35.

11. Baughcum AE, Burklow KA, Deeks CM, Powers SW, Whitaker RC. Maternal feeding practices and childhood obesity: a focus group study of lowincome mothers. Arch Pediatr Adolesc Med. 1998;152:1010-1014.

12. Gross RS, Mendelsohn AL, Fierman AH, Hauser NR, Messito MJ. Maternal infant feeding behaviors and disparities in early child obesity. Child Obes. 2014;10: 145-152.

13. Polk S, Thornton RJ, Caulfield L, Munoz A. Rapid infant weight gain and early childhood obesity in lowincome Latinos and non-Latinos. Public Health Nutr. 2016;19:1777-1784.

14. Pan L, May AL, Wethington H, Dalenius K, Grummer-Strawn LM. Incidence of obesity among young U.S. children living in low-income 
families, 2008-2011. Pediatrics. 2013; 132:1006-1013.

15. Ogden CL, Carroll MD, Kit BK, Flegal KM. Prevalence of childhood and adult obesity in the United States, 2011-2012. JAMA. 2014;311:806-814.

16. Radesky J, Miller AL, Rosenblum KL, Appugliese D, Kaciroti N, Lumeng JC. Maternal mobile device use during a structured parent-child interaction task. Academic Pediatr. 2015;15:238-244.

17. Radesky JS, Kistin CJ, Zuckerman B, et al. Patterns of mobile device use by caregivers and children during meals in fast food restaurants. Pediatrics. 2014;133:e843-e849.

18. Golen RB, Ventura AK. Mindless feeding: is maternal distraction during bottle-feeding associated with overfeeding? Appetite. 2015;91:385-392.

19. Golen RP, Ventura AK. What are mothers doing while bottle-feeding their infants? Exploring the prevalence of maternal distraction during bottlefeeding interactions. Early Hum Dev. 2015;91:787-791.

20. Matheson DM, Killen JD, Wang Y, Varady A, Robinson TN. Children's food consumption during television viewing. Am J Clin Nutr. 2004;79: 1088-1094.

21. Brunstrom JM, Mitchell GL. Effects of distraction on the development of satiety. Br J Nutr. 2006;96:761-769.

22. Long S, Meyer C, Leung N, Wallis DJ. Effects of distraction and focused attention on actual and perceived food intake in females with non-clinical eating psychopathology. Appetite. 2011;56:350-356.

23. Pew Research Center. Mobile technology fact sheet. http://www.pewinternet. org/fact-sheets/mobile-technology-factsheet/. Accessed April 6, 2017.

24. Pew Research Center. The state of the digital divide. http://www.pewinternet. $\operatorname{org} / 2013 / 11 / 05 /$ the-state-of-digital-dividesvideo-slides/. Accessed April 6, 2017.

25. Pew Research Center. U.S. smartphone use in 2015.http://www.pewinternet.org/ 2015/04/01/us-smartphone-use-in-2015/. Accessed April 6, 2017.

26. Fomon SJ. Nutrition of Normal Infants. St. Louis, MO: Mosby; 1993.

27. Wright P, Fawcett J, Crow R. The development of differences in the feeding behaviour of bottle and breast fed human infants from birth to two months. Behav Proc. 1980;5:1-20.

28. Crow RA, Fawcett JN, Wright P. Maternal behavior during breast- and bottle-feeding. J Behav Med. 1980;3: 259-277.

29. Ventura AK, Golen RP. A pilot study comparing opaque, weighted bottles with conventional, clear bottles for infant feeding. Appetite. 2015;85:178-185.

30. Putnam SP, Helbig AL, Gartstein MA, Rothbart MK, Leerkes E. Development and assessment of short and very short forms of the infant behavior questionnaire-revised. J Pers Assess. 2014;96: 445-458.

31. Thompson AL, Mendez MA, Borja JB, Adair LS, Zimmer CR, Bentley ME. Development and validation of the Infant Feeding Style Questionnaire. Appetite. 2009;53:210-221.

32. Llewellyn $\mathrm{CH}$, van Jaarsveld $\mathrm{CH}$, Johnson L, Carnell S, Wardle J. Development and factor structure of the Baby Eating Behaviour Questionnaire in the Gemini birth cohort. Appetite. 2011;57:388-396.

33. Charmaz K. Grounded theory: objectivist and constructivist methods. In: Denzin K, Lincoln YS, eds. Handbook of Qualitative Research. Thousand Oaks, CA: Sage; 2000:509-536.

34. Landis JR, Koch GG. The measurement of observer agreement for categorical data. Biometrics. 1977;33:159-174.

35. Thorn B, Tadler C, Huret N, et al. WIC Participant and Program Characteristics: Final Report 2014. Alexandria, VA: Department of Agriculture, Food and Nutrition Service; 2015. Prepared by Insight Policy Research under Contract No. A G-3198-C-11-0010.

36. Dewey KG, Lonnerdal B. Infant selfregulation of breast milk intake. Acta Paediatr Scand. 1986;75:893-898.

37. Fomon SJ, Filer LJ Jr, Thomas LN, Anderson TA, Nelson SE. Influence of formula concentration on caloric intake and growth of normal infants. Acta Pediatr Scand. 1975;64:172-181.

38. Bowlby J. The making and breaking of affectional bonds. I. Aetiology and psychopathology in the light of attachment theory: an expanded version of the Fiftieth Maudsley Lecture, delivered before the Royal College of Psychiatrists,
19 November 1976. Br J Psychiatry. 1977; 130:201-210.

39. Bowlby J. Attachment theory and its therapeutic implications. Adolesc Psychiatry. 1978;6:5-33.

40. Bowlby J. The making and breaking of affectional bonds. II. Some principles of psychotherapy: the fiftieth Maudsley Lecture. Br J Psychiatry. 1977;130: 421-431.

41. Black MM, Aboud FE. Responsive feeding is embedded in a theoretical framework of responsive parenting. J Nutr. 2011;141:490-494.

42. Engle PL, Pelto GH. Responsive feeding: implications for policy and program implementation. $J$ Nutr. 2011;141:508-511.

43. Hurley KM, Cross MB, Hughes SO. A systematic review of responsive feeding and child obesity in high-income countries. J Nutr. 2011;141:495-501.

44. Skala K, Chuang RJ, Evans A, Hedberg AM, Dave J, Sharma S. Ethnic differences in the home food environment and parental food practices among families of low-income Hispanic and African-American preschoolers. J Immigrant Minority Health. 2012;14: 1014-1022.

45. Berolo S, Steenstra I, Amick BC 3rd, Wells RP. A comparison of two methods to assess the usage of mobile hand-held communication devices. $J$ Occup Environ Hyg. 2015;12:276-285.

46. Hodges EA, Johnson SL, Hughes SO, Hopkinson JM, Butte NF, Fisher JO. Development of the responsiveness to child feeding cues scale. Appetite. 2013; 65:210-219.

47. Brown A, Arnott B. Breastfeeding duration and early parenting behaviour: the importance of an infant-led, responsive style. PLoS One. 2014;9: e83893.

48. Fildes A, van Jaarsveld $\mathrm{CH}$, Llewellyn C, Wardle J, Fisher A. Parental control over feeding in infancy: influence of infant weight, appetite and feeding method. Appetite. 2015; 91:101-106.

49. Jansen E, Mallan KM, Byrne R, Daniels LA, Nicholson JM. Breastfeeding duration and authoritative feeding practices in first-time mothers. J Hum Lact. 2016;32:498-506. 


\section{CONFLICT OF INTEREST}

The authors have not stated any conflicts of interest. 